\title{
The anterior combined approach via a single skin injection site allows lower limb anesthesia in supine patients
}

\author{
[Une méthode antérieure combinée utilisant un seul site d'injection cutanée \\ permet l'anesthésie des membres inférieurs chez des patients en décubitus dorsal]
}

Pierre Pandin MD, Nathalie Vancutsem MD, Jean Corentin Salengros MD, Isabelle Huybrechts MD, Arlette Vandesteene MD PhD

Purpose: Lower limb anesthesia (LLA) requires the combination of, at least, three-in-one and sciatic nerve (SCN) blocks. Anterior approaches are easier to perform with minimal discomfort in supine patients, specially for traumatology. Feasibility of a single needle entry combined approach is reported.

Clinical features: The combined landmark was applied in 119 ASA I and II patients (32-68 yr) scheduled for surgery below the knee. Needle (nerve stimulation applied through a single I 50-mm long b-bevelled insulated needle) was inserted at the midpoint between the two classical approaches. Thirty and $15 \mathrm{~mL}$ of $0.5 \%$ ropivacaine were injected close to the femoral and the SCN, respectively. During the following $45 \mathrm{~min}$, the extent of sensory block and knee and ankle motor block were assessed.

Landmarks were determined within $1.7 \mathrm{~min}(0.7-2.2 \mathrm{~min})$. The entire procedure was performed within $4.2 \mathrm{~min}$ (2.9-7.1 $\mathrm{min})$ from the determination of the landmark to the SCN infiltration. The three-in-one technique was successful in $89.9 \%$ while SCN was successful in $94.9 \%$. Femoral and tibial nerves were always blocked. Blockade of the posterior cutaneous femoral nerve was observed in $78 \%$ of patients. The extent and the quality of the sensory block always allowed surgery. Additional iv sedation was needed in $32.6 \%$ of patients. Motor block (adapted Bromage's scale > 2) was observed in the femoral (98.3\%), the obturator (84.8\%), the tibial (97.4\%) and the common peroneal (85.7\%) nerve distributions. No important adverse effects were recorded.

Conclusion: The anterior combined approach via a single needle entry represents a technically easy and reliable technique to perform LLA in the supine patient.
Objectif : L'anesthésie des membres inférieurs (AMI) exige la combinaison, au moins, d'un bloc trois-en-un et d'un bloc du nerf sciatique (NSC). L'abord antérieur est plus facile et n'entraîne qu'un inconfort minimal chez des patients en décubitus dorsal, surtout en traumatologie. Nous présentons l'application d'une technique combinée comportant un seul site d'injection.

Éléments cliniques : Les repères combinés ont été utilisés chez I 19 patients d'état physique ASA / et II, de 32 à 68 ans, devant subir une opération sous le genou. L'aiguille (stimulation nerveuse appliquée avec une aiguille isolée, biseautée, de $150 \mathrm{~mm}$ ) a été insérée au centre des deux points d'abord habituels. Des doses de 30 et $15 \mathrm{~mL}$ de ropivacaïne à $0,5 \%$ ont été respectivement injectées près du nerf fémoral et du NSC. Pendant les 45 min suivantes, l'étendue du bloc sensitif et du bloc moteur au genou et à la cheville a été évaluée. Les repères ont été déterminés en 1,7 min (0,7-2,2 min). L'application de la technique a demandé 4,2 min (2,9-7, I min) à partir de l'identification du repère jusqu'à l'infiltration du NSC. La technique du troisen-un a été réussie dans 89,9\% des cas et celle du NSC dans $94 \%$. Les nerfs fémoral et tibial ont été aussi anesthésiés. Le bloc du nerf cutané fémoral postérieur a été observé chez $78 \%$ des patients. L'étendue et la qualité du bloc sensitif ont permis l'opération dans tous les cas. Une sédation iv complémentaire a été nécessaire chez 32,6\% des patients. Le bloc moteur (échelle de Bromage > 2) a été observé pour les territoires des nerfs suivants : fémoral (98,3\%), obturateur (84,8\%), tibial (97,4\%) et sciatique poplité externe (85,7\%). Aucun effet indésirable important n'a été enregistré.

Conclusion : La méthode antérieure combinée comportant un seul site d'injection est une technique facile et fiable pour réaliser une AMI chez le patient en décubitus dorsal.

From the Department of Anesthesiology and Resuscitation, Erasmus Hospital, Free University of Brussels, Brussels, Belgium.

Address correspondence to: Dr. Pierre C. Pandin, Department of Anesthesiology and Resuscitation,

Erasmus Hospital, route de Lennik 808, B-1070 Brussels, Belgium. Fax: 32-2-555-43-63; E-mail: ppandin@ulb.ac.be

Department and institution of attribution of the work: Department of Anesthesiology and Resuscitation, Erasmus Hospital, Brussels,

Belgium.

Accepted for publication March 3, 2003.

Revision accepted July 4, 2003. 
$\mathrm{L}$

OWER limb anesthesia is more and more often considered an effective solution to perform surgery of the knee and below. Although clinicians claim that the sciatic nerve is deep and difficult to locate at the hip or the thigh level by an anterior approach, the feasibility of a combined approach, via a single skin needle entry, in supine patients is reported.

\section{Material and methods}

This prospective study was approved by the Institutional Review Board of the Free University of Brussels Erasmus Medical School. Informed consent was obtained.

\section{Anatomic landmarks}

With the patient supine, the lower limb in neutral position with a thin pillow under the knee, the classical Winnie's ${ }^{1}$ and Beck's ${ }^{2}$ landmarks were drawn (Figure 1). The cutaneous projection of the femoral artery corresponded to point A (Figure 1). Point B (Figure 1) matched Beck's ${ }^{2}$ point. Midpoint $\mathrm{C}$ (Figure 1) on the line $\mathrm{AB}$ represented needle entry $(\mathrm{A}-\mathrm{C}$ and $\mathrm{B}-\mathrm{C}$ : distances of $4-5 \mathrm{~cm}$ ).

\section{Anesthetic technique}

Local anesthesia consisted, first, in a $45^{\circ}$ superficial and cephalad injection $(3 \mathrm{~mL})$ and, second, an $80^{\circ}$ deep and caudad infiltration $(5 \mathrm{~mL})$ of $1 \%$ lidocaine. A sin- gle $150 \mathrm{~mm}$ insulated b-bevelled Stimuplex $\mathrm{A}^{\mathrm{TM}}$ (BBraun $^{\mathrm{TM}}$ Melsungen AG, Germany) needle connected to an HNS Stimuplex ${ }^{\mathrm{TM}}$ (BBraun ${ }^{\mathrm{TM}}$ Melsungen AG, Germany) stimulator $(0.1 \mathrm{msec}$ stimulus at $2 \mathrm{~Hz}$ frequency with an initial current intensity of $1 \mathrm{~mA}$ ) was inserted at point $\mathrm{C}$. First a modified three-in-one technique was performed. For this, the needle was advanced carefully from point $\mathrm{C}, 45^{\circ}$ cephalad and $10^{\circ}$ medially, to point A (Figure 2) until movement of the patella related to the femoral nerve stimulation (5-6 $\mathrm{cm}$ depth) was observed. The needle was never advanced more than $8 \mathrm{~cm}$ during this phase. Nerve stimulator output was decreased to $0.5 \mathrm{~mA}$ to optimize needle placement. After a negative test dose $(3 \mathrm{~mL} 1 \%$ lidocaine with $1 / 200,000$ epinephrine), $30 \mathrm{~mL}$ of $0.5 \%$ ropivacaine were injected (incrementally). Thereafter, the needle was withdrawn to the $s c$ tissue and redirected $10^{\circ}$ laterally and $80^{\circ}$ caudad (Figure 2 ). If the tip met the anterior medial surface of the femur (5-6 cm depth) the needle was reoriented medially. Within a depth of 9-13 cm the sciatic nerve was identified by the stimulation of its common peroneal (dorsiflexion or eversion of the foot) or its tibial compound (plantar flexion or inversion of the foot and flexion of the toes). Fifteen millilitres of $0.5 \%$ ropivacaine were injected following the same procedure.

TABLE Success rate, onset, duration and complications of the anterior combined approach in 119 ASA I-II patients

\begin{tabular}{|c|c|c|c|c|}
\hline & & $\begin{array}{l}\text { Number of patients/ } \\
\text { success rate }\end{array}$ & $\begin{array}{l}\text { Onset (min) } \\
\text { mean /SD (range) }\end{array}$ & $\begin{array}{l}\text { Duration (br) } \\
\text { mean /SD (range) }\end{array}$ \\
\hline \multicolumn{5}{|l|}{ Sensory block } \\
\hline \multicolumn{2}{|l|}{ Femoral nerve } & $119 / 100$ & $15.4 / 17.4(10-30)$ & $10.6 / 22.9(5.5-23)$ \\
\hline \multicolumn{2}{|l|}{ Obturator nerve } & $107 / 89.9$ & $15.8 / 9.8(12-30)$ & \\
\hline \multicolumn{2}{|c|}{ Lateral femoral cutaneous nerve } & $102 / 85.7$ & $16.1 / 22.9(14-34)$ & \\
\hline \multicolumn{2}{|c|}{ Saphenous nerve } & $119 / 100$ & $15.4 / 24(10-30)$ & \\
\hline \multicolumn{2}{|l|}{ Tibial nerve } & $119 / 100$ & $17.6 / 20.8(12-34)$ & $10.9 / 30.9(5-22)$ \\
\hline \multicolumn{2}{|c|}{ Superficial peroneal nerve } & $119 / 100$ & $17.1 / 29.5(12-36)$ & \\
\hline \multicolumn{2}{|c|}{ Deep peroneal nerve } & $113 / 94.9$ & $17.7 / 22.9(12-30)$ & \\
\hline \multicolumn{2}{|c|}{ Posterior femoral cutaneous nerve } & \multicolumn{3}{|c|}{ Motor block } \\
\hline \multicolumn{2}{|l|}{ Femoral nerve } & $117 / 98.3$ & $28.3 / 28.4(16-40)$ & $9.3 / 24(4.5-19)$ \\
\hline \multicolumn{2}{|l|}{ Obturator nerve } & $101 / 84.8$ & $26.6 / 29.5(16-42)$ & \\
\hline \multicolumn{2}{|l|}{ Tibial nerve } & $116 / 97.4$ & $28.6 / 20.8(14-36)$ & $8.2 / 26.2(4.0-18)$ \\
\hline \multicolumn{2}{|c|}{ Common peroneal nerve } & $102 / 85.7$ & $29.1 / 21.8(16-38)$ & \\
\hline \multicolumn{5}{|l|}{ Complications } \\
\hline \multirow[t]{4}{*}{ Paresthesia } & \multicolumn{2}{|c|}{ Needle advancement - femoral procedure } & $9 / 7.5$ & \\
\hline & \multicolumn{2}{|c|}{ Needle advancement - sciatic procedure } & $7 / 5.8$ & \\
\hline & \multicolumn{2}{|c|}{ Femoral anesthetic solution injection } & $6 / 5$ & \\
\hline & \multicolumn{2}{|c|}{ Sciatic anesthetic solution injection } & $5 / 4.2$ & \\
\hline \multirow[t]{2}{*}{ Vascular puncture } & \multicolumn{2}{|c|}{ Femoral procedure } & $0 / 0$ & \\
\hline & \multicolumn{2}{|c|}{ Sciatic procedure } & $1 / 0.75$ & \\
\hline
\end{tabular}

ASA $=$ American Society of Anesthesiologists SD $=$ standard deviation. 


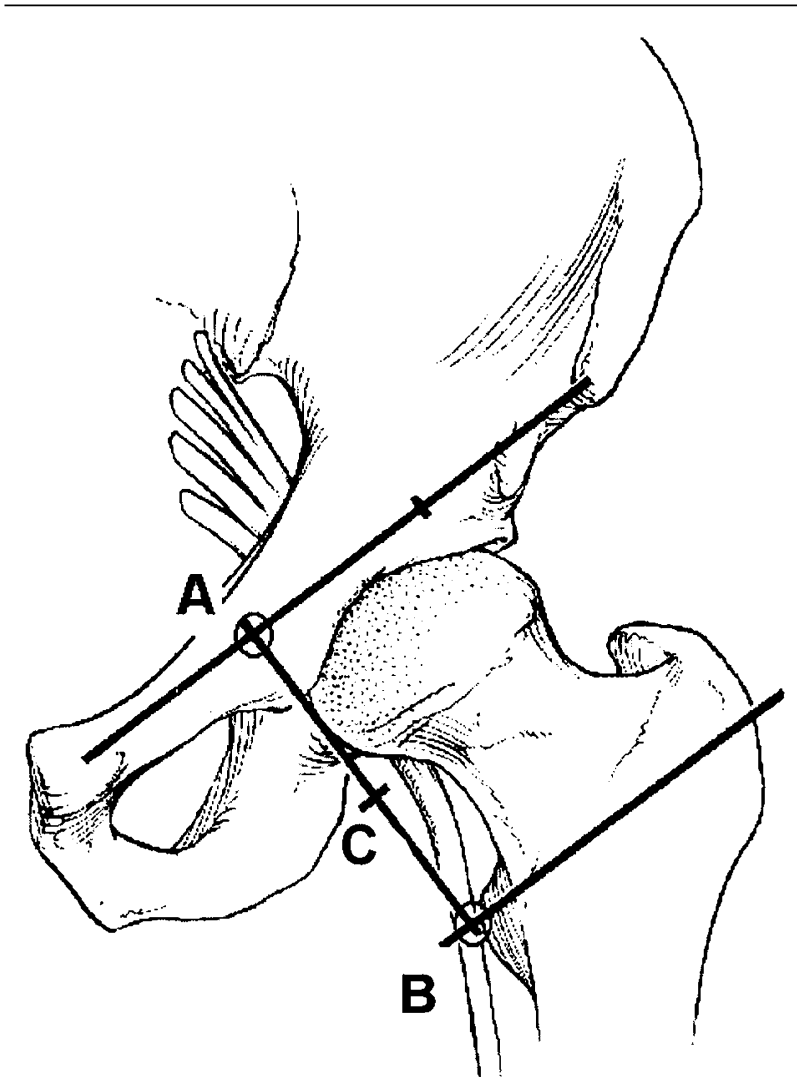

FIGURE 1 Anatomical landmarks of the anterior combined approach

The classical landmarks of the paravascular inguinal or three-inone approach and the anterior sciatic nerve approach were marked. The femoral artery corresponded to point $\mathrm{A}$ and point $\mathrm{B}$ matched the classical puncture site of the anterior sciatic nerve block. The midpoint $\mathrm{C}$ on line $\mathrm{A}$ to $\mathrm{B}$ represented the needle insertion site for the single puncture technique $(\mathrm{A}-\mathrm{C}$ and $\mathrm{B}-\mathrm{C}$ distances of $4-5 \mathrm{~cm}$ ).

\section{Block follow-up}

Sensory and motor block were assessed by an investigator unaware of the technique used every five minutes for $45 \mathrm{~min}$. Sensory block was assessed using the cold and pinprick tests in the different cutaneous supplies of the femoral, lateral cutaneous femoral, obturator, common peroneal and tibial nerves. Motor block was evaluated according to the modified Bromage's ${ }^{3}$ scale adapted to the femoral and the obturator nerves ( $\mathrm{l}$ to 4 with $\mathrm{l}$ = full extension of the knee for femoral nerve or adduction of the thigh for obturator nerve, and $4=$ total motor block) or to the common peroneal and the tibial nerves ( 1 to 4 with $1=$ full dorsal or plantar flexion of the foot for common peroneal or

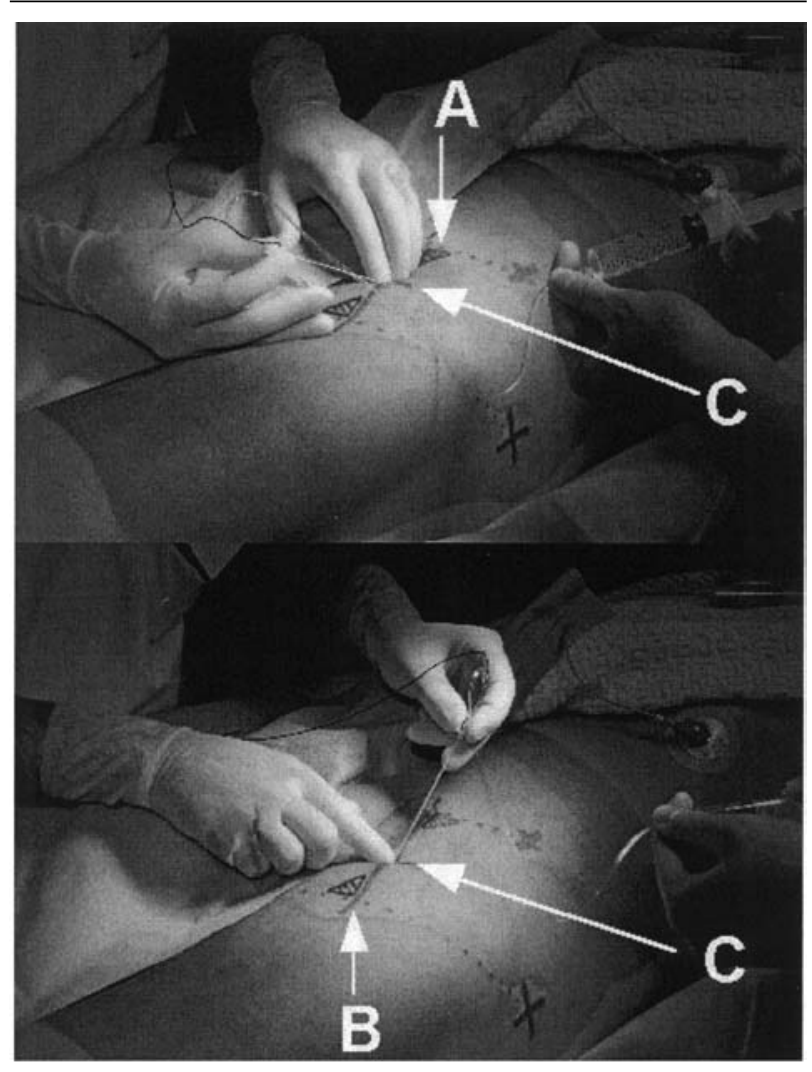

FIGURE 2 Upper, the b-bevelled needle is advanced carefully from the puncture point $\mathrm{C}, 45^{\circ}$ cephalad and $10^{\circ}$ medially to the lateral face of the artery (A) to elicit femoral nerve stimulation (5-6 cm depth). Lower, the b-bevelled needle is redirected $10^{\circ}$ laterally and $80^{\circ}$ caudad. Within a depth of $9-13 \mathrm{~cm}$ the sciatic nerve is identified by eliciting stimulation of its common peroneal nerve or its tibial nerve component.

tibial nerve, and $4=$ total motor block). Adverse effects were recorded during this period.

Results are presented as means, standard deviations (SD) and ranges using the SPSS 8.0 software (SPSS Inc, Chicago, IL, USA).

\section{Results}

The anterior combined approach was performed by five anesthesiologists in 119 American Society of Anesthesiologists physical status I and II patients (37 males and 82 females), aged 32 to $68 \mathrm{yr}$ (mean of 51.2 ) and operated for knee and below knee surgical procedures. Mean weight and height were $78.1 \pm 21.2$ $\mathrm{kg}$, and $171.4 \pm 19.6 \mathrm{~cm}$, respectively. Surgery lasted 
$76.4 \mathrm{~min}$ (SD 31.7, range 47-148). The femoral nerve was found at a mean depth of $5.7 \mathrm{~cm}$ (SD 0.6, range 4.7-6.8) and the sciatic nerve at a mean depth of $11.2 \mathrm{~cm}$ (SD 0.8, range 9.3-12.8). The femoral nerve was successfully located at the first attempt in all patients and the sciatic nerve after one $(21.3 \%)$, two (71.3\%) or three $(7.4 \%)$ attempts. The determination of the landmark required $1.7 \mathrm{~min}$ (SD 0.7, range 0.7-2.2). The procedure was completed within 4.2 min (SD 0.6, range 2.9-7.1) from the beginning of the landmark determination to the sciatic nerve infiltration. The sciatic nerve failed to be located four times and it was decided to proceed under general anesthesia.

A single case of vascular puncture was recorded during approach of the sciatic nerve in an obese female in whom nerve localization was difficult (three attempts). No other problem was recorded during performance of the block.

Sensory and motor block, onset and duration and complications are summarized in the Table. Sensory block corresponds to total suppression of cold or pinprick sensation. Complete lower limb anesthesia was reported in 95 patients $(79.8 \%)$. Even when incomplete, sensory blockade always allowed the surgery.

Sedation (midazolam 2-3 $\mu \mathrm{g} \cdot \mathrm{kg}^{-1}$ and sufentanil $\left.0.05-0.1 \mu \mathrm{g} \cdot \mathrm{kg}^{-1}\right)$ was administered in 12 patients $(10 \%)$ because of pain during the block and in 25 patients $(22.6 \%)$ because of tourniquet pain (always after at least a 50 -min period).

No hemodynamic adverse event (arterial hyper or hypotension) or toxicity (seizure, arrhythmia, etc.) were reported. Finally, no delayed paresthesia or dysesthesia, no sensory or other motor deficits were reported during the postoperative period.

\section{Discussion}

Our results demonstrate the clinical effectiveness of this anterior combined lower limb block, even if a true three-in-one block is encountered only in $85.7 \%$ and, otherwise, must be considered as a two-in-one or a femoral nerve block. They are similar to those published previously regarding the onset and duration time of the three-in-one $e^{4}$ and the sciatic ${ }^{5,6}$ nerve blocks performed separately using ropivacaine. The relatively high failure rate of the posterior femoral cutaneous nerve block (22\%) represents the main weakness of the technique (tourniquet tolerance). Anatomical variations of the location of this nerve relative to the sciatic nerve are a problem. Nerve location failures concerned only the sciatic nerve, but were infrequent $(3.3 \%)$. This must be considered in the present context ${ }^{6-10}$ whereby attempts are made to enhance the anterior access to the sciatic nerve by different means (external rotation of the limb, shift of needle entry, new landmarks). Moving the needle insertion point cephalad (point B-C), in our approach, generates a 20 to $25^{\circ}$ angle to the vertical direction, which facilitates progress of the needle towards the sciatic nerve, just caudad to the lesser trochanter, decreasing the risk of a painful puncture of the femoral periosteum.

\section{Conclusion}

We conclude that this technically easy and reliable combined anterior approach to perform lower limb anesthesia can be considered a valuable alternative to traditional multiple punctures especially in supine patients who cannot be mobilized easily because of trauma, arthrosis, arthritis, etc.

\section{References}

1 Winnie AP, Ramamurthy $S$, Durrani $Z$. The inguinal paravascular technic of lumbar plexus anesthesia. The "3-in-1 block". Anesth Analg 1973; 52: 989-96.

2 Beck GP. Anterior approach to sciatic nerve block. Anesthesiology 1963; 24: 222-4.

3 Bromage PR. Epidural Analgesia. Philadelphia: W.B Saunders; 1978.

4 Marhofer P, Oismuller C, Faryniak B, Sitzwobl C, Mayer $N$, Kapral S. Three-in-one blocks with ropivacaine: evaluation of sensory onset time and quality of sensory block. Anesth Analg 2000; 90: 125-8.

5 Casati A, Fanelli G, Borghi B, Torri G. Ropivacaine or $2 \%$ mepivacaine for lower limb peripheral nerve blocks. The Study Group on Orthopedic Anesthesia of the Italian Society of Anesthesia, Analgesia, and Intensive Care. Anesthesiology 1999; 90: 1047-152.

6 Chelly JE, Delaunay L. A new anterior approach to the sciatic nerve block. Anesthesiology 1999; 91: 1655-60.

7 Hadzic A, Reiss W, Dilberovic F, et al. Rotation of the leg influences ability to approach the sciatic nerve through the anterior approach. Reg Anesth Pain Med 1998; 23: 38-40.

8 Vloka JD, Hadzic A, April E, Thys DM. Anterior approach to the sciatic nerve block: the effects of leg rotation. Anesth Analg 2001; 92: 460-2.

9 Ericksen $M L$, Swenson JD, Pace NL. The anatomic relationship of the sciatic nerve to the lesser trochanter: implications for anterior sciatic nerve block. Anesth Analg 2002; 95: 1071-4.

10 Van Elstraete AC, Poey C, Lebrun T, Pastureau F. New landmarks for the anterior approach to the sciatic nerve block: imaging and clinical study. Anesth Analg 2002; 95: 214-8. 